\title{
Finding Information Framework: A Tool to Teach Life-Long Learning Skills
}

Molly Cohen-Osher, MD, MMedEd | Theresa A. Davies, PhD | David B. Flynn, MS | Megan E. Young, MD I Miriam Hoffman, MD

PRiMER. 2021;5:16.

Published: 5/26/2021 | DOI: 10.22454/PRiMER.2021.934572

\section{Abstract}

Introduction: In this age of rapid information expansion, medical education can no longer be taught solely by information acquisition, but rather requires information management and information mastery at both the point of learning as well as at the clinical point of care. We must teach our trainees how to ask, categorize, and answer their own questions-skills required to be a life-long learner. We developed the Finding Information Framework (FIF), a conceptual algorithm as well as web-based tool and app, to guide medical students in asking and categorizing their questions and to link them directly to the most appropriate information resource for their questions. Here we assess the functionality of the FIF following its implementation in the first-year medical school curriculum problem-based learning (PBL) course.

Methods: First-year medical students $(n=126)$ utilized the FIF in their longitudinal problem-based learning course discussion groups and completed an anonymous survey.

Results: Qualitative and quantative data suggest that the FIF was easy to use (86.5\%), supported the course curriculum (80\%), and helped students find relevant information to answer their questions (77\%) from trusted reliable resources (70\%). Qualitative comments also suggest that the FIF is initially a helpful tool during the PBL course but becomes less useful over time as students become more familiar with resources.

Conclusion: The FIF assists students in identifying trusted resources and in efficiently and effectively finding answers to questions at the point of learning. These data suggest that students are internalizing the tool's conceptual algorithm over time, reinforcing the teaching of information management and information mastery.

\section{Introduction}

In this age of rapid information expansion, medical education can no longer be structured solely around information acquisition. Educators need to teach the concepts and lifelong learning skills of information management and information mastery ${ }^{1-3}$ to be used both at the point of learning and later applied in the clinical setting at the point of care.

Furthermore, this generation of medical students must access information electronically, a modality which 
provides information from resources with a wide range of validity and relevance. It is therefore critical that students develop their foundational approaches to information seeking in a manner that teaches them what types of resources are appropriate for each type of question. Subsequently, student can be taught how to critically assess information resources themselves. It can be challenging for medical schools to teach these concepts both because of faculty expertise and institutional resources. ${ }^{4}$

We formed an Evidence-Based Medicine (EBM) Vertical Integration Group (VIG) to develop a longitudinal, developmental, integrated EBM curriculum that teaches the skills and concepts of information management and information mastery, can be applied with faculty at all levels of knowledge and skills, and can be easily transferred to other institutions and health professions. The basis for this curriculum is the Finding Information Framework (FIF), a conceptual algorithm as well as a web-based tool and app that structures how medical students ask and categorize their questions and links them directly to the most appropriate information resource to answer their questions (Figure 1). 5,6

The FIF is a student-centered tool grounded in the concepts of adult learning, and begins with the student generating a question. It takes learners through an algorithm to define their question first by determining whether it is a background question (a question that asks for general knowledge about a process, condition, test, treatment, or thing); or a foreground question (a question that asks for specific knowledge to guide clinical decisions). ${ }^{8}$ Background is split into basic science or clinical. Clinical background is further split into common and rare/academic interest. Foreground questions are by definition always clinical, and are divided into point of care, rare/academic interest, and resources/services.

Once the student categorizes their question, the student is guided to the appropriate information resource group to answer the question. The framework is available for download through the medical school library website and the Apple IOS App Store, so students can use it with direct one-click links into the actual resources. These suggested resources were determined by the EBM VIG committee composed of medical librarians and faculty with expertise in EBM and information mastery, and customized to reflect the library's holdings and available web-based resources.

This framework and its concepts were introduced to students during their first year in their problem-based learning course, Integrated Problems (IP), and reinforced in their Essentials of Public Health Course and on several core clerkships. This study assesses the usability and functionality of the FIF following its initial implementation in the first-year curriculum, in the context of its use in the IP course.

\section{Methods}

First-year medical students and faculty were oriented to the FIF during a 1-hour lecture in the beginning of the year. They were encouraged to use the FIF when researching questions during their PBL course. This study was approved as exempt by our University's Institutional Review Board \#H-37627.

A total of 126 of the 180 (70\%) first-year students assessed the FIF by completion of an anonymous survey at the conclusion of the first-year curriculum. Students responded to questions using a 5-point Likert scale and provided feedback through open-ended responses.

\section{Results}

Results from the survey are shown in Table 1. Students felt the FIF tool promoted understanding of the different categories of information resources (73\%), helped students select the best information resource (70.6\%), helped students find relevant information to answer their clinical or basic science question (77\%), improved student information seeking efficiency (68.2\%), and was easy to use (86.5\%) and supported the IP course 
curriculum (80.2\%).

A total of 68 surveys contained open response comments on the FIF framework. The most common comment was related to the advantage of having easily accessible and trusted resources available. Additionally, ease of use and the benefit of use in their IP course were highly noted. Others comments stated that the FIF was useful initially but less so subsequently. Suggested improvements to the FIF were the time of the year it was introduced, integration into other courses, and recommendations for a quick link for the FIF webpage. See Table 2 for representative student comments.

\section{Conclusions}

These data suggest that students perceive the FIF as a tool that facilitates their ability to identify useful resources and effectively find answers to their questions at the point of learning in their first-year problembased learning course. Additionally, the limited open-ended comments suggest that students are not simply using the FIF as a tool to categorize questions and identify resources. Instead, they are internalizing the conceptual algorithm, since they report finding it less necessary over time as they develop skills in asking, categorizing, and answering their own questions. As such, it seems that the tool itself may reinforce the teaching of information management and information mastery. Further supporting the FIF's effectiveness is the limited amount of faculty development that was needed as the tool was implemented in the IP course.

This paper is limited in its scope as it focuses only on information management training for preclerkship students. Future research should evaluate the utility of the FIF for use at the point of care in the clinical setting, as well as evaluate the usability of the FIF by faculty and outside institutions and in different health professions disciplines.

The FIF provides a conceptual framework to teach concepts that can be difficult for students to master. It is a practical tool to accurately and efficiently direct students to find the answers to their questions at the point of learning in a problem-based learning course.

\section{Tables and Figures}


Figure 1: Boston University School of Medicine's Finding Information Framework

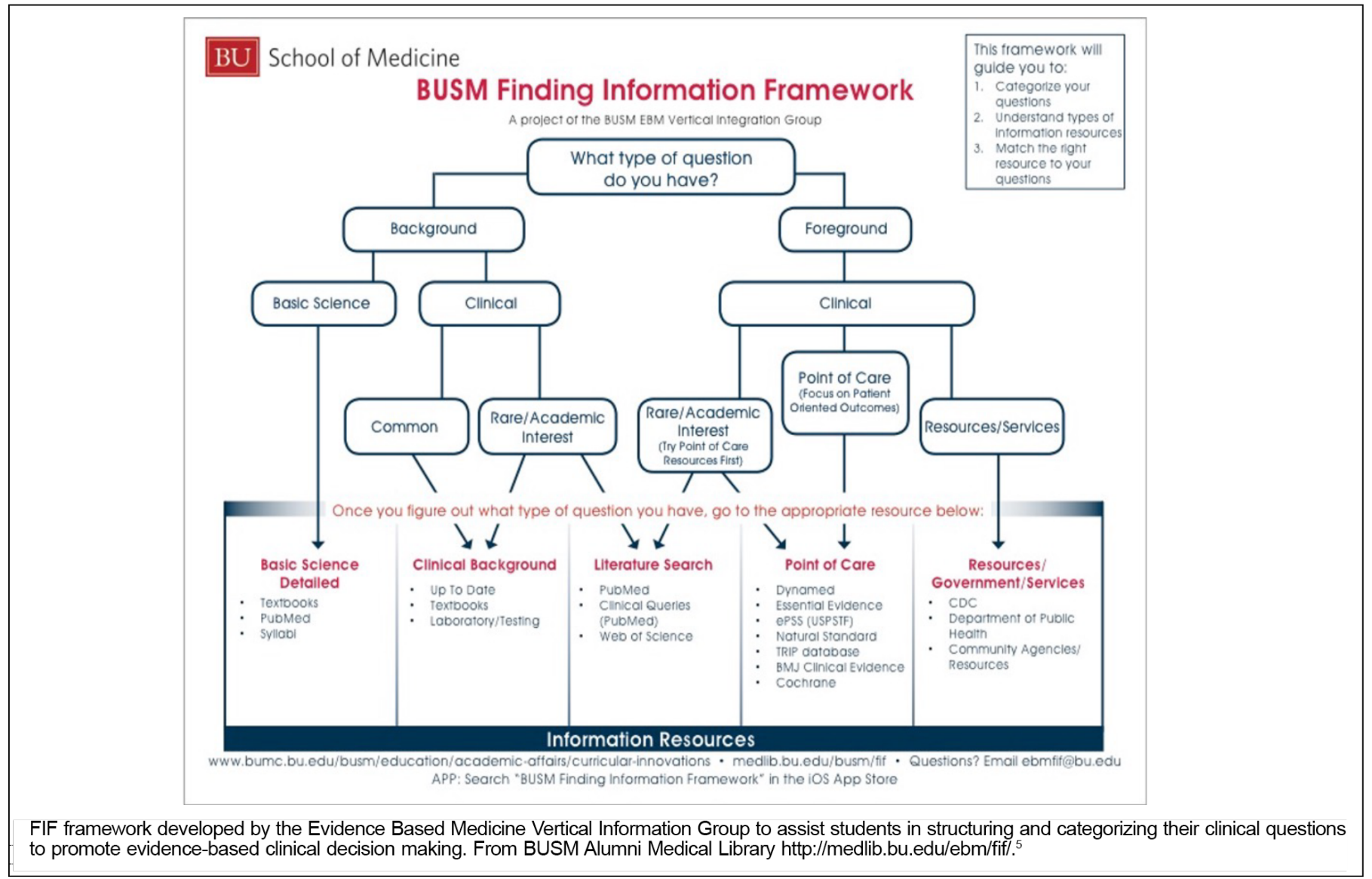

\section{Table 1: Quantitative Survey Questions and Responses of Student Perception of the Usability of the Finding Information Framework}

\begin{tabular}{|l|c|}
\hline \multicolumn{1}{|c|}{ Question } & \multicolumn{1}{|c|}{$\begin{array}{c}\text { Percentage Agree/Strongly } \\
\text { Agree (Mean) on a 5-point } \\
\text { Likert Scale (n=126) }\end{array}$} \\
\hline $\begin{array}{l}\text { The Finding Information Framework (FIF) promoted my understanding of the different } \\
\text { categories of information resources }\end{array}$ & 73.0 (3.96) \\
\hline $\begin{array}{l}\text { The FIF helped me to select the best information resource to answer my clinical or basic } \\
\text { science question }\end{array}$ & 70.6 (3.94) \\
\hline $\begin{array}{l}\text { The FIF helped me to find information that was relevant to answering my clinical or } \\
\text { basic science question }\end{array}$ & $77.0(4.05)$ \\
\hline $\begin{array}{l}\text { The FIF improved my information seeking efficiency (ie, helped me to find relevant } \\
\text { information faster) }\end{array}$ & $68.3(3.95)$ \\
\hline The FIF supported the curriculum of the Integrated Problems course & 80.2 (4.17) \\
\hline The FIF was easy to use & 86.5 (4.3) \\
\hline
\end{tabular}

Abbreviation: FIF, Finding Information Framework.

Students ( $n=126)$ evaluated the FIF using the following Likert scale: Strongly Disagree (1), Disagree (2), Neither Agree/Disagree (3), Agree (4), Strongly Agree (5). 
Table 2: Themes and Representative Comments From Student Open-Ended Responses

\begin{tabular}{|c|c|}
\hline Theme (Number of Comments) & Representative Comments \\
\hline $\begin{array}{l}\text { Advantage and availability of easily accessible } \\
\text { and trusted resources (35) }\end{array}$ & $\begin{array}{l}\text { - "Very nice to have an algorithm and aggregated resources- overall a helpful } \\
\text { tool" " } \\
\text { - Very helpful in introducing reliable and commonly used resources for } \\
\text { answering certain types of questions" }\end{array}$ \\
\hline Ease of use (18) & $\begin{array}{l}\text { - "Easy to use" } \\
\text { " "Great organization" } \\
\text { - "Straightforward" } \\
\text { - l liked that the flow chart is very clear" }\end{array}$ \\
\hline $\begin{array}{l}\text { Benefit of use in the Integrated Problems (IP) } \\
\text { course (8) }\end{array}$ & $\begin{array}{l}\text { - "It is laid out in an easy to understand manner. There is no way to be } \\
\text { confused as to how to use the page. It definitely helped shorten my } \\
\text { research time for my IP class" }\end{array}$ \\
\hline Useful initially but less so subsequently (13) & $\begin{array}{l}\text { - "Most, if not all, of our IP questions were either basic science background or } \\
\text { basic clinical background, so I got used to using UpToDate and the Access } \\
\text { medicine textbooks as resources and stopped needing to use the FIF as a } \\
\text { way to trace my research question type. However, I always went to the FIF } \\
\text { before starting my research to use it to access my needed resources" } \\
\text { - "I feel like once I understood the different categories of questions, I didn't use } \\
\text { the FIF as a way to help me define my question but rather as an easy tool } \\
\text { to get to the resource I wanted" }\end{array}$ \\
\hline
\end{tabular}

Questions:

Do you have any suggestions for improvements to the FIF, or how it is taught or applied at BUSM?

Please comment on the strengths of the FIF.

\section{Acknowledgments}

Acknowledgments: The authors thank Dr John Wiecha for his leadership and meaningful contributions to the Boston University School of Medicine EBM Vertical Integration Group.

\section{Corresponding Author}

Molly Cohen-Osher, MD, MMedEd

Boston University School of Medicine, 72 East Concord St, Medical Education Office A-3, Boston, MA 02118.

617-358-7477. Fax: 617-358-7478

mcoheno@bu.edu

\section{Author Affiliations}

Molly Cohen-Osher, MD, MMedEd - (Co-First Author) Boston University School of Medicine

Theresa A. Davies, PhD - (Co-First Author) Boston University School of Medicine

David B. Flynn, MS - Boston University School of Medicine

Megan E. Young, MD - Boston University School of Medicine

Miriam Hoffman, MD - Hackensack Meridian School of Medicine

\section{References}

1. Shaughnessy AF, Slawson DC, Bennett JH. Becoming an information master: a guidebook to the medical information jungle. J Fam Pract. 1994;39(5):489-499.

2. Slawson DC, Shaughnessy AF. Teaching information mastery: creating informed consumers of medical information. J Am Board Fam Pract. 1999;12(6):444-449. doi:10.3122/jabfm.12.6.444

3. Slawson DC, Shaughnessy AF. Teaching evidence-based medicine: should we be teaching information management instead? Acad Med. 2005;80(7):685-689. doi:10.1097/00001888-200507000-00014

4. Institute of Medicine. The Learning Healthcare System: Workshop Summary. Washington, DC: The 
National Academies Press; 2007. doi:10.17226/11903.

5. BUSM Finding Information Framework. Boston: Boston University School of Medicine; 2014. https://www.bu.edu/phpbin/medlib/ebm/fif/. Accessed May 4, 2021.

6. About the Finding Information Framework. Boston: Boston Univeristyl Alumni Medical Library; 2014. http://www.bumc.bu.edu/medlib/portals/busm/about-fif/. Accessed May 4, 2021.

7. Liu A, Davies TA, Flynn DB, Wiecha JM, Cohen-Osher M, Hoffman-Kleiner M. Novel mobile application to promote evidence-based medicine decision-making in medical education. Med Sci Educ.

2015;25(2):95-96. doi:10.1007/s40670-014-0101-7

8. Straus SE, Fracgp PGM, Richardson WS, Haynes RB. Evidence-Based Medicine: How to Practice and Teach It. 4 ed. Edinburgh: Churchill Livingstone; 2010.

Copyright $(2021$ by the Society of Teachers of Family Medicine 